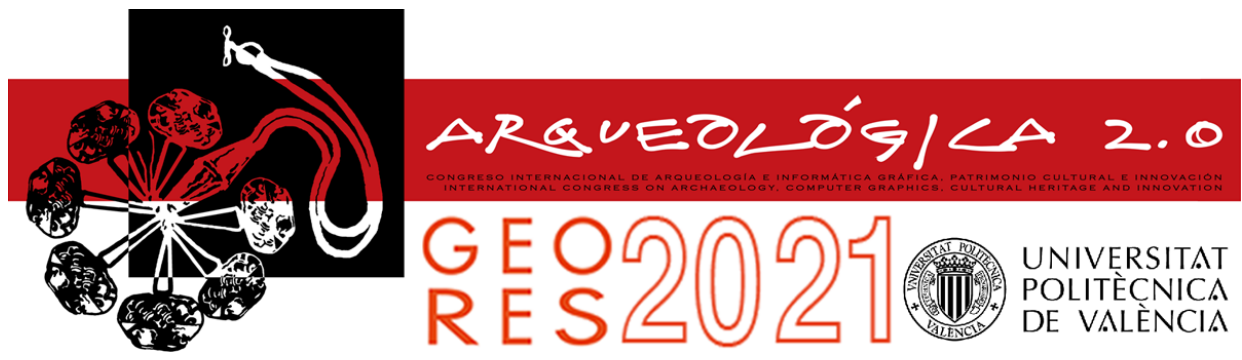

Proceedings of the joint international event $9^{\text {th }}$ ARQUEOLÓGICA

$2.0 \& 3^{\text {rd }}$ GEORES

Valencia (Spain).

26-28 April 2021

\title{
FRESCO PHOTOGRAMMETRY: DOCUMENTING THE IMPERIAL CULT CHAMBER AT LUXOR TEMPLE
}

\author{
Owen Murray \\ Owen Murray, Oriental Institute, University of Chicago, 1155 East 58th Street, Chicago Illinois, USA. omurray@ommphoto.ca
}

\begin{abstract}
:
This paper discusses the photogrammetric and epigraphic documentation of the late-Roman frescoes in the Imperial Cult Chamber at Luxor Temple by the University of Chicago's Oriental Institute, Epigraphic Survey Project. It presents a brief history of the room and an overview of research related to it, while relaying the epigraphic documentation technique and methodology employed, and the use of photogrammetry to achieve those objectives. Due to the nature, and timing, of the project, this paper explores the intersection of traditional epigraphic documentation methods with more recent digital trends and how these toolsets have been adapted and adopted into a print publication workflow by the Survey. Of note is the relationship of GSD to specific scale reproduction ratios and print resolutions for traditional 2D publications, as well as how this translates into the number of points $\mathrm{per} / \mathrm{m}^{2}$ in a 3D dense cloud.
\end{abstract}

Keywords: Luxor temple, imperial cult chamber, fresco, photogrammetry, digital epigraphy, cultural heritage

\section{Introduction}

The Luxor Temple complex (Fig. 1) is located on the East bank of the Nile River in what was ancient Thebes (modern-day Luxor). Constructed during the late Bronze Age (New Kingdom) between the $14^{\text {th }}$ and $13^{\text {th }}$ centuries BCE, like many of the major temple complexes throughout Egypt, it has stood witness to history ever since - through several phases of subsequent Pharaonic expansion, then Greek, Roman, early Christian, Coptic and Islamic additions and modifications. Considered a tourist attraction even in antiquity, now, at the beginning of the Anthropocene, the site finds itself both benefactor and victim of mass tourism, with guides that oft neglect and/or confuse its rich and varied past.

Perhaps the best example of this can be found in the Imperial Cult Chamber, (also called the Emperor's Chambers or King's Room), located at the heart of the temple between the Portico of Amenhotep III (A III) and the Barque Shrine (Fig. 2).

As part of an $18^{\text {th }}$ Dynasty addition by Amenhotep III, the room was originally a sanctuary devoted to the divine Pharaoh - the eight papyrus-bundle columns within supporting abaci, sandstone architraves and flat sandstone roof blocks. As its current name suggests, the room went through a significant transformation during the late-Roman reformations of Diocletian, finding itself altered to occupy the Principia position of standard Roman fortifications. Roman builders converted the room by removing the columns, blocking the original doorway leading to the barque shrine and rooms beyond, and installing a niche. A canopy supported by four granite Corinthian columns was placed directly in front of the niche, thereby drawing attention to it and centering it as a focal point not only in the room, but along axial fault lines of the temple complex at large (Fig. 3).

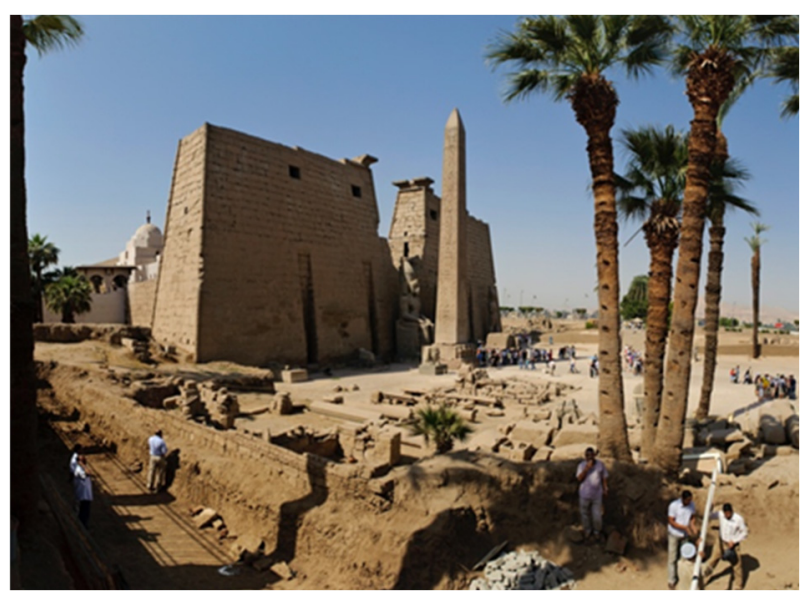

Figure 1: Luxor Temple. General view of Luxor Temple from the North East. Murray/ARCE 2009.

In addition to height modifications of the walls themselves, the A III $18^{\text {th }}$ Dynasty wall reliefs in the room were covered entirely with plaster and then decorated with Roman frescoes celebrating the imperial cult of the first four lateRoman rulers (tetrarchs). The niche was painted with a dado upon which the four tetrarchs, depicted in imperial purple mantles, float in nebulous semi-divinity - Diocletian himself represented with the attributes of Jupiter, holding a spear in his raised right hand while cradling a globus in his left. Between the two more senior and central Augusti, a floating bust of Jupiter was most likely painted, while in the semi-dome directly above them references to Jupiter ensue with a zoomorphic representation - an eagle with 
outstretched wings clutches a gilded and bejeweled oak corona (see Fig. 23).

As such, these frescoes are the only example of monumental paintings from the tetrarch era remaining in situ, and perhaps the finest preserved Roman paintings in Egypt.

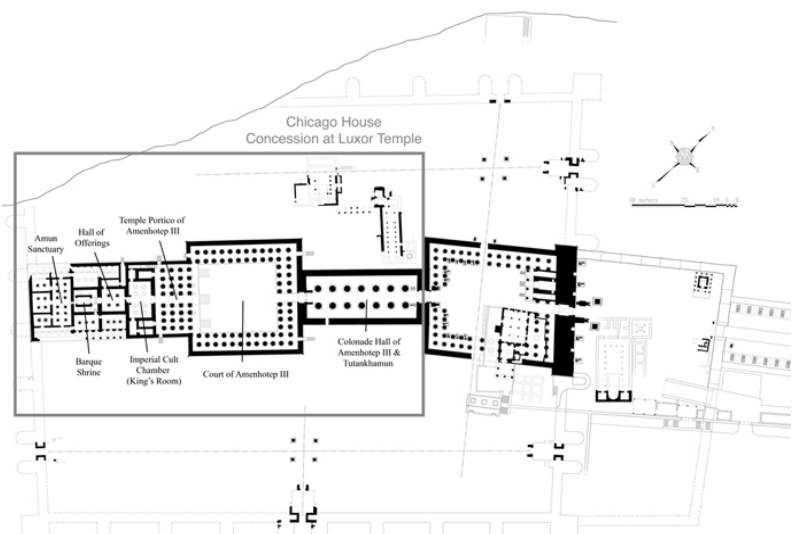

Figure 2: Luxor Temple Plan. Location of the Imperial Cult Chamber (in red). Heidel/The Epigraphic Survey 2015.

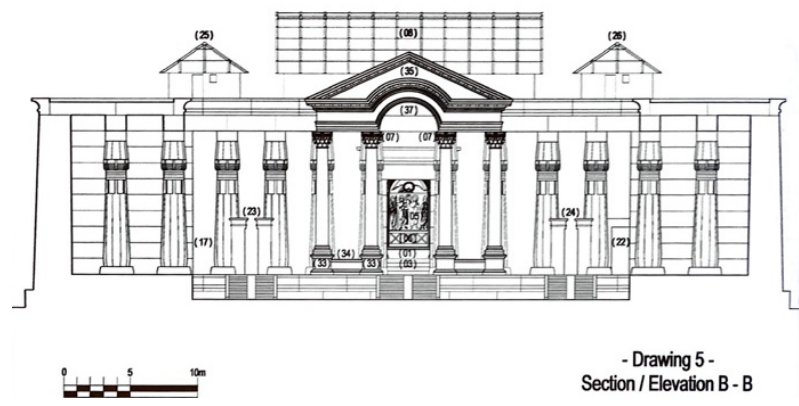

Figure 3: Hypothetical Elevation. View of Imperial Cult Chamber apse through the Alll Portico Facade; after Heidel 2015, fig 3.11 .

\section{Background}

Covered in debris along with the rest of the temple complex, the Imperial Cult Chamber was most likely excavated during the winter of $1853-1854$ by Victor Gustave Maurnier, a French photographer and antiquities dealer whom also served as the unofficial French consul in Luxor. Watercolours from two different sources (George de Sausmarez, 1855 \& John Gardner Wilkinson, 1856) provide glimpses of the room shortly thereafter (Fig. 4 ), as well as rare colour information, however a definitive set of tracings that were supposedly completed by Urbain Bouriant have never come to light.

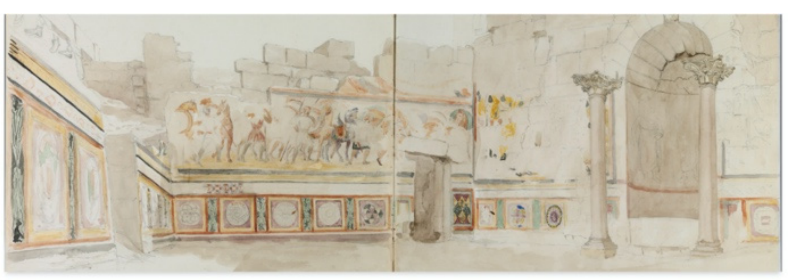

Figure 4: J.G. Wilkinson Watercolour. View of Imperial Cult Chamber shortly after excavation from Wilkinson's sketchbook 25V \& 26R, after Jones 2015, fig A.1.
Slowly, over the following century, more was learnt about the paintings and their origins, and confusion over their provenance - early Christian church vs. Iate Roman tetrarchy - definitively established (Monneret de Villard, 1953). But despite such knowledge, the quality of artisanship, and the relevance of the frescoes, it wasn't until the 1970's that detailed conservation efforts took place under a team led by J.G. Deckers. Indeed, it is due largely to his reframing and presentation of the Imperial Cult Chamber within a modern archeological context (Fig. 5 ) that led to American Research Center in Egypt (ARCE) conservation efforts (Jones, 2015), and it is in turn from this project, that the photogrammetric and epigraphic documentation methods detailed below, follow.

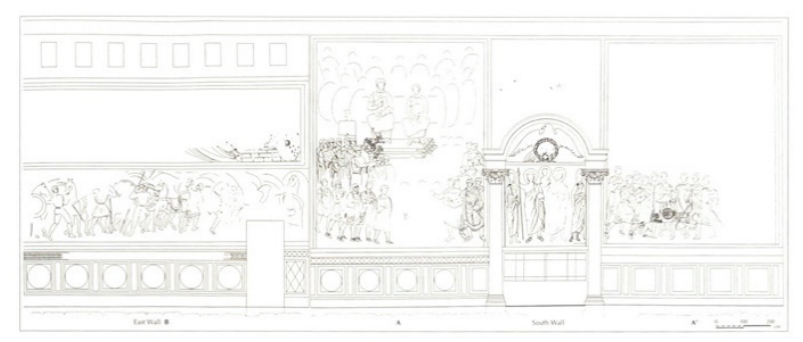

Figure 5: Deckers Reconstruction. Reconstruction of the Imperial Cult Chamber frescoes, after Deckers 1979, Fig. 34.

From 2005 - 2008 an ARCE conservation project led by Michael Jones involved a team of Italian wall painting conservators working in conjunction with the Epigraphic Survey of the Oriental Institute, University of Chicago, towards the project's objectives: cleaning, recording and documenting the frescoes in situ, followed by publication. The Epigraphic Survey provided large format colour film as well as digital photography before, during and after conservation, and these photographs, paired with chemical analysis from the Italian conservators, provided an invaluable record of the frescoes and understanding of pigment makeup at a molecular level. In 2015, Art of Empire (Jones \& McFadden eds. 2015) was published and stands as the exemplar work of scholarship on the frescoes; tying together multiple disciplines and perspectives and honouring the Imperial Cult Chamber by chronicling its history and interlocutors from antiquity until the present moment. In line with Deckers' publication of the state of conservation as of 1979 (Fig. 6), the Italian conservators on the ARCE project made detailed drawings outlining areas of extant plaster and paint layers (Fig. 7), as well as multiple conservation records of visual impediment, detachment, cavity filling and overall cleaning.

These works complement one another and are interesting comparisons. Although the former appears slightly more nuanced in execution to the latter, it is clear what areas of the fresco suffered degradation during the quarter century between them. It should be noted that although both sets of drawings are 'to scale', they are best considered approximations, as their dimensions neither match one another, nor the actual dimensions of the wall itself. This is especially clear in the ARCE documentation of the unraveled, perspective corrected niche whose doorway remains the same width as the uncorrected one as seen in situ, a fact that is as implausible as it is inaccurate (Fig. 8) That said, insofar as providing a snapshot of conservation state both perform their job admirably, and in Deckers publication, provided the base upon which his 
reconstruction of the painted frescoes was informed (see Fig. 5, above).
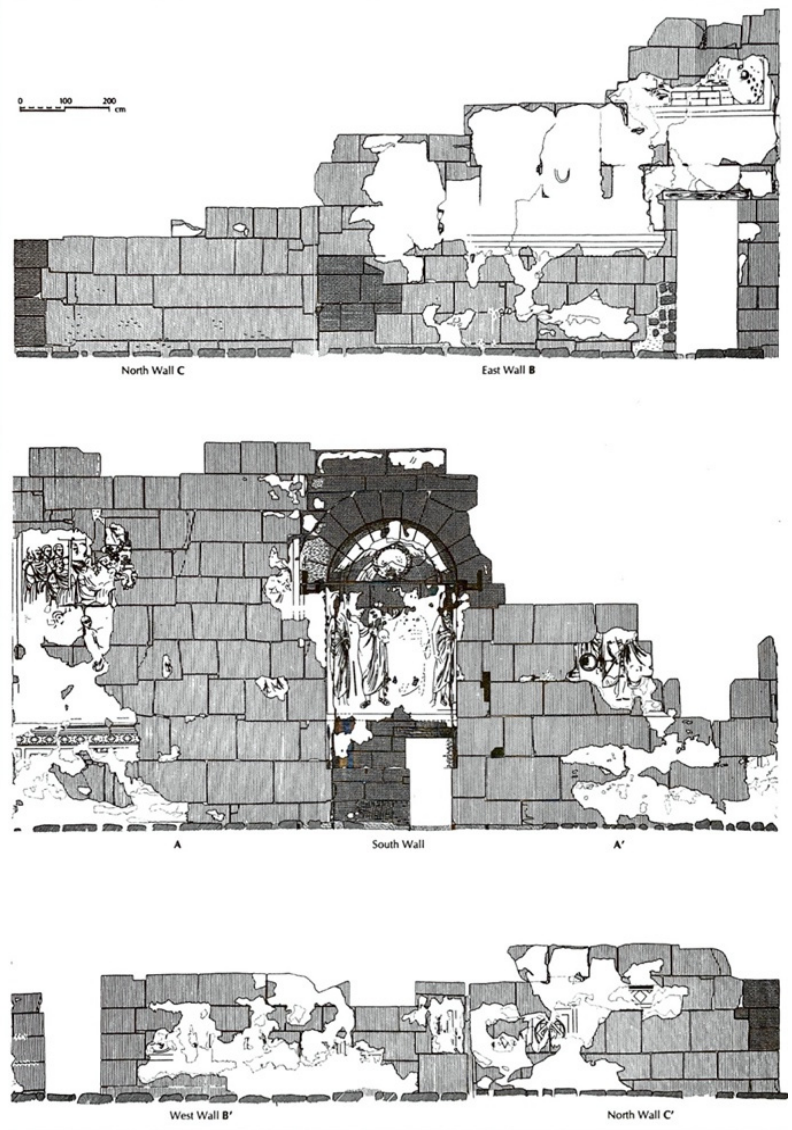

Figure 6: Conservation State. Deckers' publication of the state of conservation of the Imperial Cult Chamber as of 1979, after Deckers 1979, fig. 33.

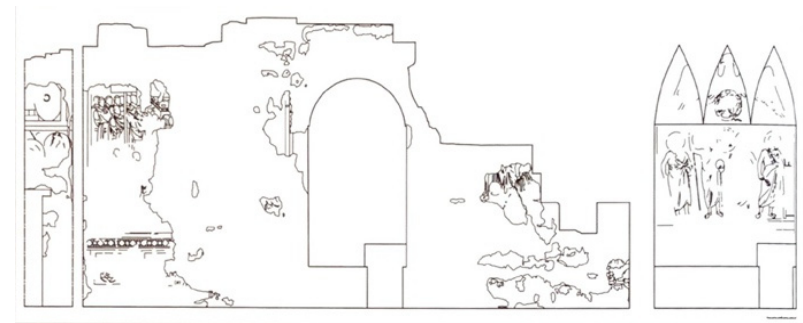

Figure 7: Conservation State. ARCE publication of the state of conservation on the south wall of the Imperial Cult Chamber as of 2005, after De Cesaris, Sucato \& Ricchi 2015, fig. 5.2.
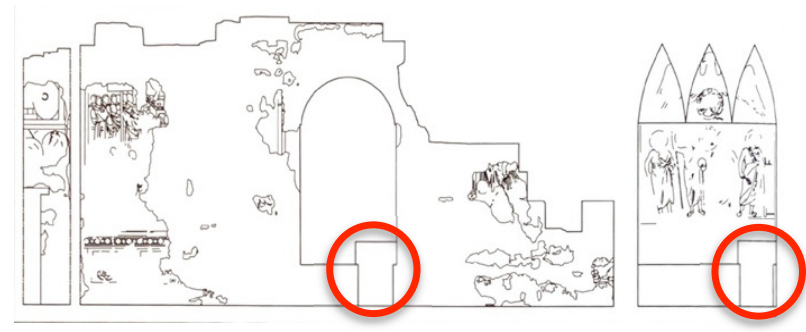

Figure 8: Conservation State. ARCE publication of the state of conservation on the south wall as of 2005; (problematic perspective corrected niche doorway in red), after De Cesaris, Sucato \& Ricchi 2015, fig. 5.2.
In 2013, Epigraphic Survey documentation efforts furthering Deckers' invaluable archaeological contextualization began. Following the tried-and-true scientific methodology for epigraphy devised by James Henry Breasted at the inception of the project in 1924, this documentation relied on a multidisciplinary approach underpinned by rectified large format photography, onsite observation and drawing by skilled artists, and a series of checks of the facsimile line drawing against the original carried out by specialized philologists. As Breasted realized early on in his quest for an accurate epigraphic documentation technique - although film photography purported to be an ideal one-stop documentation solution, its impartial nature placed equal emphasis on all surface elements thereby highlighting none. Paired with directional lighting concerns, but even more so - the illusion of reality - he came to realize there was no replacement for rectified photography paired with the skilled hand of artist and keen observation of a specialized Egyptologist in front of the source material. Understood as the gold standard of documentation in epigraphy circles, this technique has come to be known as the Chicago House Method (McClain, 2020). In light of the ever-increasing use, and reliance on SfM documentation techniques, many of the same problems that Breasted encountered with the medium of photography and are applicable to photogrammetry today, only compounded, as the illusion has sidled into the third dimension. Virtually real, or really virtual? (Huggett, 2019). As Breasted surmised nearly 100 years ago, Epigraphic Survey Assistant Director Brett McClain (2020) states categorically today: there is no substitute for taking the time to make multiple examinations of the wall, with multiple collations of the copy against the original.

In the case of the frescoes, although a plethora of film and digital photographs were taken from 2005 - 2008, their dimensions paired with the sheer volume of work required to maintain high quality results proved challenging for both the Survey photographer and artist involved. This was due in part to technological constraints: mainly, the Epigraphic Survey's reliance on large format film photography and an inability to unravel and "flatten" the niche, thus providing a standard, suitable photographic enlargement from which the traditional Chicago House Method (McClain, 2020) could unfurl.

\section{Documentation Technique \& Methodology}

Despite first class conservation efforts, a closer look at the frescoes revealed the ravages of time multiplied by exposure to the elements; much of the top layer of painting containing the bulk of details was gone. Occasionally, only paint scars were preserved, with very little pigment remaining on the surface. In some instances, the traces did not form any recognizable features, thus the main goal of the epigraphic recording was to isolate the visible pigment and synthesize the data detectable on the surface. It was clear that by reducing the traces to mere line drawing, as both Deckers and the Italian conservators had done, that one could not register all of the remaining traces of paint on the wall, not to mention accurately capture the style of the original artisanship. Since extensive colour photographs taken before, during and after the 2005 - 2008 conservation provided a complete record of every preserved shade, 
hue and tint of the paintings, the epigraphic drawing method focused on the strict clarification of all detectable features on the walls, in grey scale. After numerous trials to test out different styles of representation, it was determined that outline drawings paired with pigment texture in various combinations produced a suitable solution that balanced original painting style with an accurate recording of the fresco conservation state postcleaning (Fig. 9 \& Fig. 10) (Vértes, 2019).
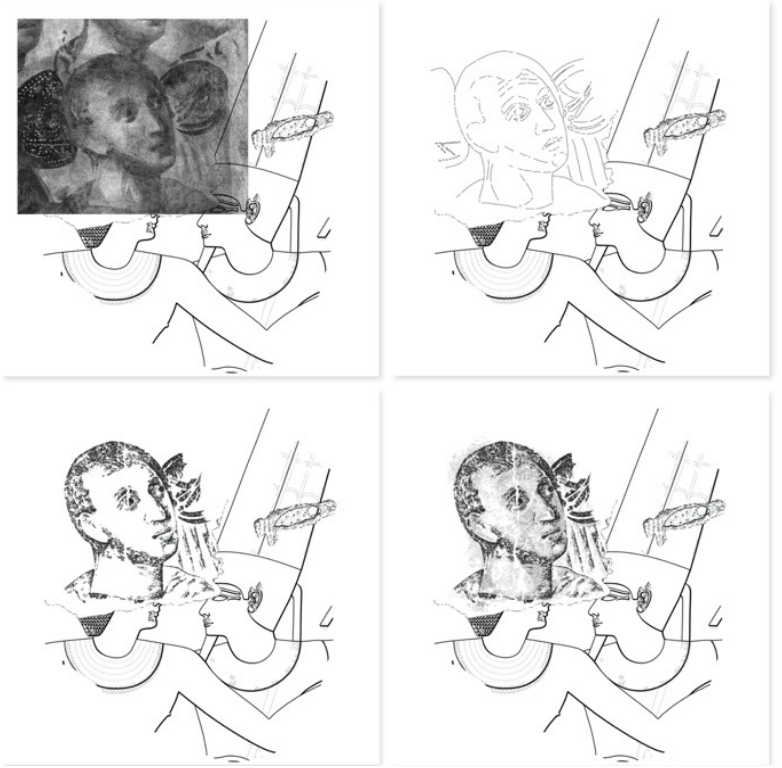

Figure 9: Epigraphic Drawing Trial. Mock up area used to test different epigraphic representations. Vértes 2019.

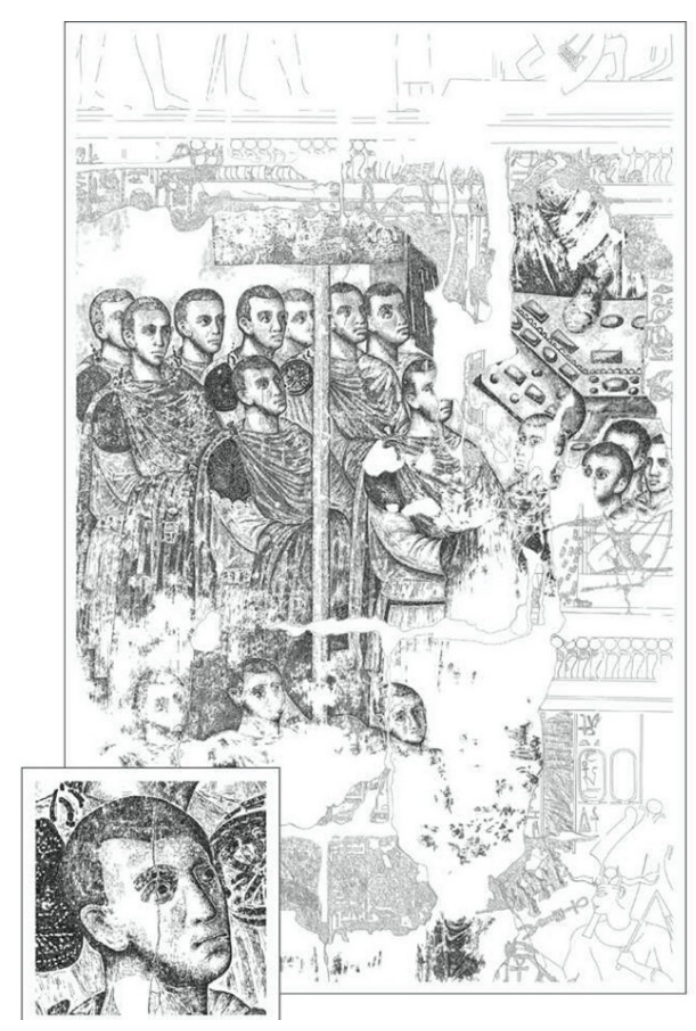

Figure 10: Epigraphic Drawing Sample \& Detail.

Representation of the late Roman frescoes on the south east wall in the Imperial Cult Chamber, courtesy of the Oriental Institute of the University of Chicago; after Vértes 2020, fig III.7.4).
As the sole artist involved in this epigraphic documentation, and with a case study required to adapt digital documentation workflows, Krisztián Vértes developed a hybrid approach, blending the Epigraphic Survey's tried-and-true traditional methods with more recent digital trends.

The bulk of in situ documentation on the east wall as well as the south wall to the east of the niche followed the traditional Chicago House Method outlined briefly below.

Large format 1:4 scale black and white film negatives of the walls were printed by Survey photographer Yarko Kobylecky, which Vértes verified as accurate through a series of comparison measurements. Then, observing the wall carefully, he began mechanically penciling texture directly on top of the photograph, employing a hand held light shone from multiple directions on the wall to ensure veracity of what was being recorded. A crosshatched texturing technique was adopted to represent the graphical impression of the scenes - already in-and-ofitself a departure from the traditional outline drawing applied to Pharaonic relief. Vértes reinforced every discernible trace of pigment by adding pencil marks with variable strength, slowly forming a textural impression of the paintings on paper (Fig. 11).
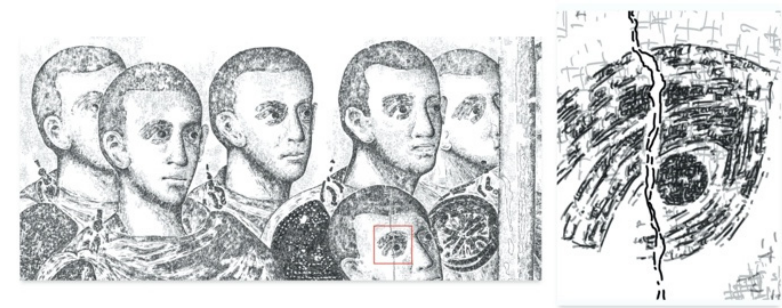

Figure 11: Crosshatch Texturing Technique. Textural impression of paintings on paper using pencil marks with variable strength. Vértes 2019.

While effective and manageable in small sections, applying the technique wholesale to over $60 \mathrm{~m}^{2}$ encompassing the east and eastern portion of the south wall became overly time consuming and problematic, not only for Vértes but also Kobylecky, as each penciled enlargement subsequently needed to be immersed in an iodine solution causing the photographic emulsion to dissolve, leaving only the pencil drawing of pigment texture on photo paper. This bleached drawing then needed to be scanned in high resolution before receiving final studio treatment.

In 2015, experiments with an iPad Pro opened up new possibilities for onsite recording. Although Vertés had experimented with lugging a laptop and Wacom Cintiq into the field since 2013, drawing in Photoshop proved cumbersome and unwieldy, plagued by concerns with external power, file size and the resulting lag between stylus/cintiq and the laptop running Photoshop. The first generation of iPad Pros, and accompanying Apple Pen paired with the ProCreate app realized an experience much closer to drawing on paper by hand. Its portability, lack of external power issues, and stylus hand pressure sensitivity and responsiveness opened up the first real possibilities of drawing digitally onsite. However, despite this much welcomed possibility, the first-generation iPad Pros didn't have enough processing power to be able to handle the amount of information the frescoes held at 1:4 @ 1200ppi. Indeed, the maximum file size on the 
ProCreate App was (and remains) 8K, which in turn dictates the maximum tile size that can be handled in the field. Viewed strictly in terms of pixel count, the maximum number of pixels a ProCreate file can handle is $+/-67 \mathrm{M}$ px; the number of pixels in just $1 \mathrm{~m}^{2} @ 1200$ ppi is $+/-2.2 \mathrm{~B}$ px. The entire frescoes cover approximately $160 \mathrm{~m}^{2}$, and Vertés was employing a crosshatch technique building up layers of information resulting in large file sizes, rather than a traditional line drawing, which generates smaller files when saved.

Rather than get bogged down in cross hatching minutiae, Vertés put the iPad Pro to use recording the original $18^{\text {th }}$ dynasty A III wall reliefs upon which the frescoes were plastered, and that in turn, were required to provide context. To keep the process as close to a physical pencilon-enlargement method as possible, these line drawings were done in the Procreate app. This required careful planning beforehand, with the division of large master orthomosaic files on a more powerful studio computer done first, before parceling smaller, downscaled sections suitable for transfer to the iPad for drawing onsite.

The creation of these large master orthomosaics was done photogrammetrically and begun by the author during the 2016-2017 field season (Fig 12). The north east, north west, west and south west walls of the Imperial Cult Chamber were photographed in such a manner for fresco documentation, while in turn, doubling as backgrounds for the $18^{\text {th }}$ Dynasty Pharaonic reliefs (Fig. 13) An added bonus of these high resolution photogrammetric orthomosaics was the colour information included (not to mention the 3D datasets from which they were derived!).

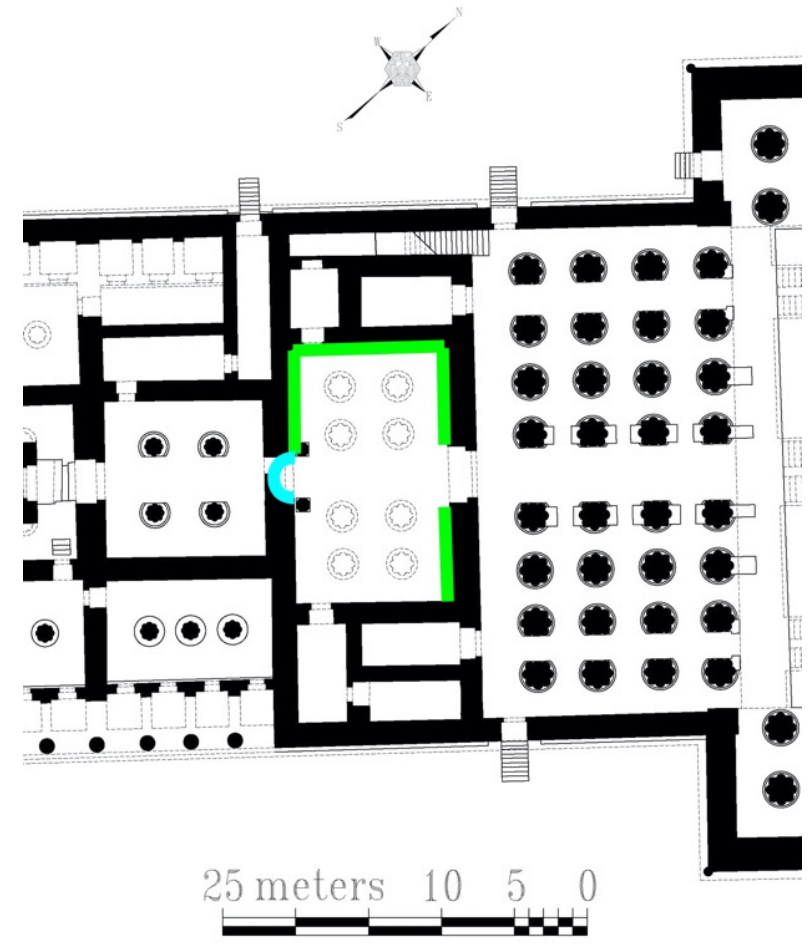

Figure 12: Areas Documented using Photogrammetry. Areas documented using photogrammetry; 2016-2017 field season in green, 2017-2018 field season in blue. Murray/The Epigraphic Survey 2017.

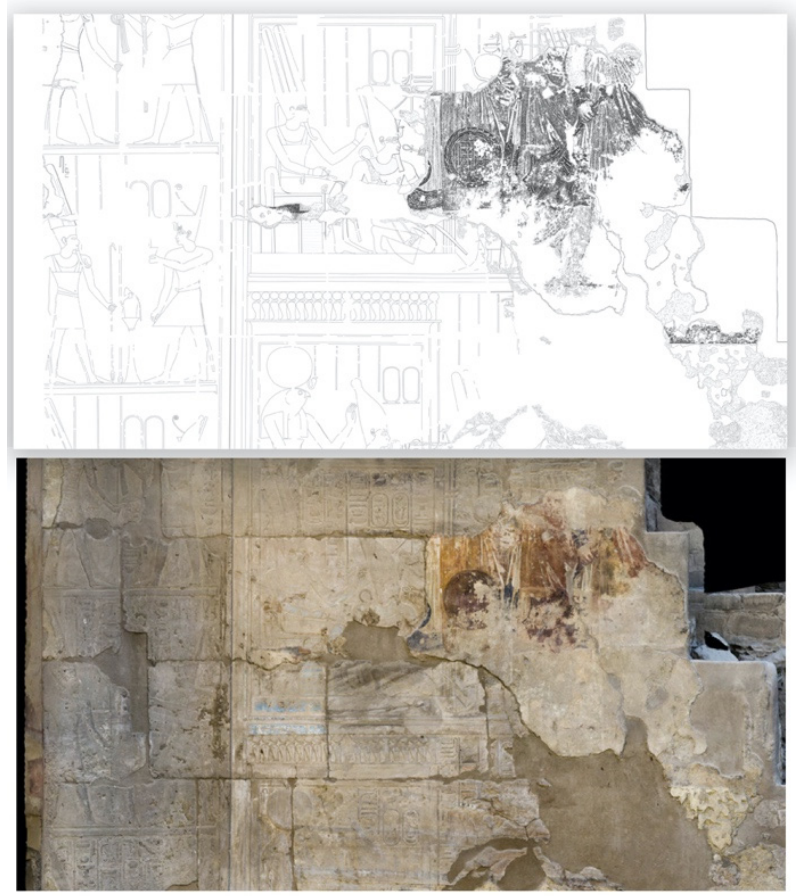

Figure 13: Drawing from Photogrammetry. Sample of drawing (top) from photogrammetric orthomosaic (bottom) on the south west wall, used for fresco documentation as well as inscribed Alll Pharaonic material behind. Vértes, Murray/The Epigraphic Survey 2017, 2018.

This was a first in the Survey's epigraphic operations and further negated the need for separate colour film negative documentation post black and white drawing enlargement, as well as providing a robust set of 3D information and measurements hitherto unimaginable.

\section{Fresco photogrammetry}

In order to meet the requirements of the Survey's digital inking and large folio print publication standards, any digital drawing enlargements or orthomosaics need to be produced at a 1:4 scale @ 1200ppi. In photogrammetric terms this involves a correlation between the Ground Sampling Distance (GSD) - formulaic in nature, depending on the sensor size, lens used and distance to/from the object - with the print resolution and desired scale required for publication, which can be tricky as the photogrammetric application used to process the datasets, Agisoft PhotoScan (now Metashape), renders orthomosaic results as 1:1@72ppi. This means that results will always adhere to the actual dimensions of the subject at hand (given a series of controlled measurements are taken and equipment has been properly calibrated), regardless of the size of the sensor used to achieve it. So, what is in question is not the veracity of the results in terms of accuracy and precision, but its resolution in terms of the number of pixels that represent any given real-world dimension. 10px may represent $1 \mathrm{~m}$ or $1000 \mathrm{px}$ may represent $1 \mathrm{~m}$, or $10000 \mathrm{px}$ may represent $1 \mathrm{~m}$; the result with the highest degree of fidelity in terms of measurement on screen is inevitably the image with the highest number of pixels, especially as most screens now are capable of more than the classic 72ppi and work anywhere in a range of between 200 500 ppi. Going forward, display resolution capabilities will only increase, both in physical dimension and number of 
pixels. In print, although there is often a misconstrued relationship between ppi and dpi, an image with a higher pixel count will inevitably give the printer more information to work with regardless of its dpi capabilities. The default print resolution for most inkjet printers is between 300 $600 \mathrm{dpi}$, while high end printing presses are upwards of 1000 dpi. Regardless of interpolation and smart upscaling algorithms, printed at a scale of $1: 1$, the result with the highest degree of fidelity to its real-world companion will be the image with the highest pixel count per any given real-world dimension. This point is oft neglected as most print publications do not need to reproduce, nor concern themselves with reproducing, results at 1:1 - however, for a digital twin cable of producing a physical facsimile at various scales, the point cannot be overstated enough.

In order to realize the aforementioned 1:4 scale @ $1200 p p i$ a $0.0845 \mathrm{~mm} / \mathrm{px}$ ratio is required. However, due to processing limitations of the first-generation iPad Pros and the aforementioned file size restrictions of the Procreate app, Vértes requested the drawing enlargements for the fresco documentation at 1:4 @ 400 ppi $\left(1 \mathrm{~m}^{2}=+/-250 \mathrm{M} \mathrm{px}\right)$. This requires a $0.254 \mathrm{~mm} / \mathrm{px}$ ratio. To obtain this, a Mamiya RZ67 Pro IID and MamiyaSekor Z $50 \mathrm{~mm}$ f/4.5 (prime/fixed lens) mounted with a Hasselblad CFV-50C digital back were used for photography. Images were shot handheld from a distance of 1.5 - 2m, RAW at 1/125@ $\mathrm{f} / 8.5-16$ and ISO 100-800 (the 2.5 stop aperture difference was used to make incremental adjustments as required while onsite; ISO 100 was used for direct sunlight; ISO 800 for shadow) (Fig. 14). Scaffolding was used to achieve the right vertical ( $Z$ ) height, and a series of coded targets were placed in corner positions with long horizontal, vertical, and diagonal measurements taken to accurately scale the results.

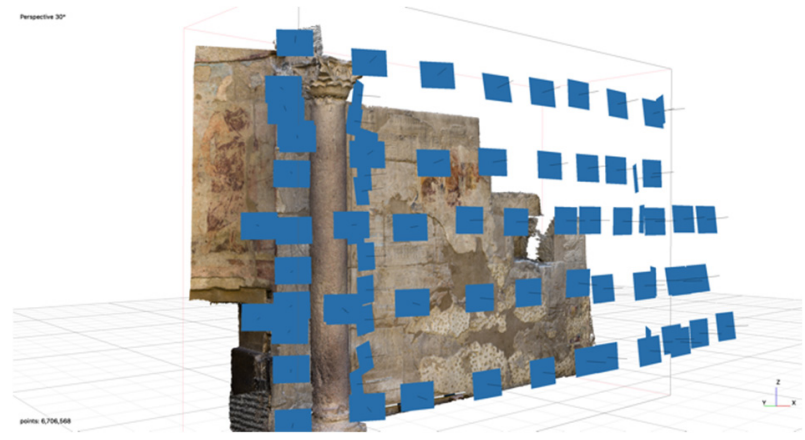

Figure 14: Camera Positions on the SW Wall. Screenshot of the camera positions on the south west wall of the Imperial Cult Chamber. Murray/The Epigraphic Survey 2017.

The method of data acquisition followed standard photogrammetric overlap rules of $2 / 3$ rds (Chandelier, Egels, Héno \& Schelstraete, 2013) in all directions and in most cases erred higher. Because the frescoes were relatively flat and uncomplicated in their architecture, save for the apse, only one pass from the $1.5-2 \mathrm{~m}$ distance was needed. The exception to this was the remaining Corinthian column on the south west wall, next to the apse. Because of the limited distance between column and wall $(+/-0.65 \mathrm{~m})$ two sets of photos were shot from either side on an angle as close to perpendicular to the wall as possible (Fig. 15). This allowed a result both with, and without, the column to be produced (Fig. 16).

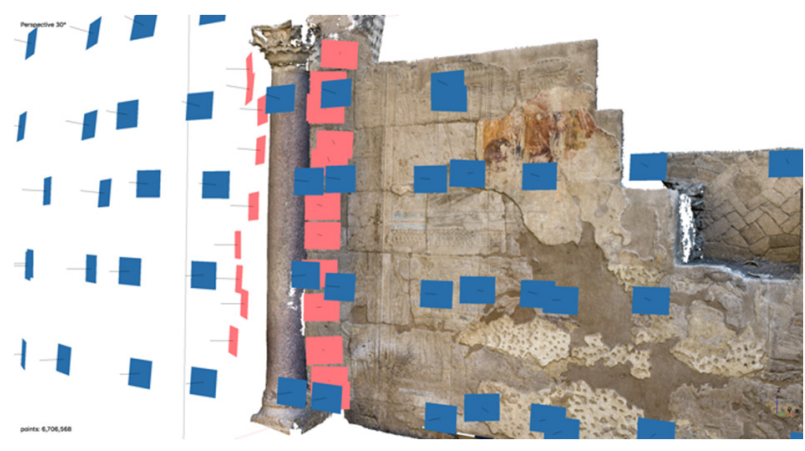

Figure 15: Corinthian Column Camera Positions. Screen shot of the camera positions used to photograph behind the column on the south west wall of the Imperial Cult Chamber. Murray/The Epigraphic Survey 2017.

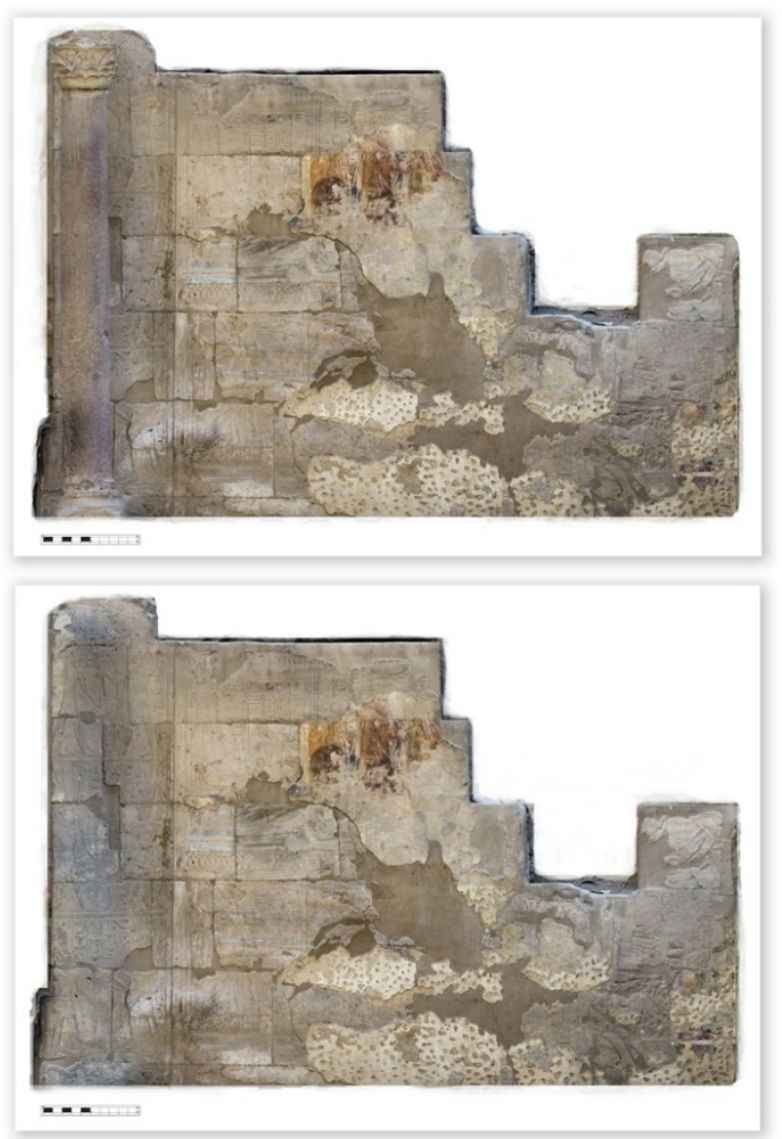

Figure 16: SW Wall With and Without Column. The south west wall of the Imperial Cult Chamber with (top) and without (bottom) the column, shot in diffused indirect ambient sunlight. Murray/The Epigraphic Survey 2017.

All of the photographs were shot using natural sun light, timed to specific periods of the day in order to obtain the desired result. The north walls were shot in the morning in direct, raking sunlight from the east (Fig. 17), and the south west wall was shot in the early afternoon while in shadow in diffused indirect ambient sunlight (see Fig. 16). The west wall was shot twice as requested by Vértes; both at midday, in direct raking sunlight from the south, as well as later in the afternoon while in shadow in diffused indirect ambient light (Fig. 18). 

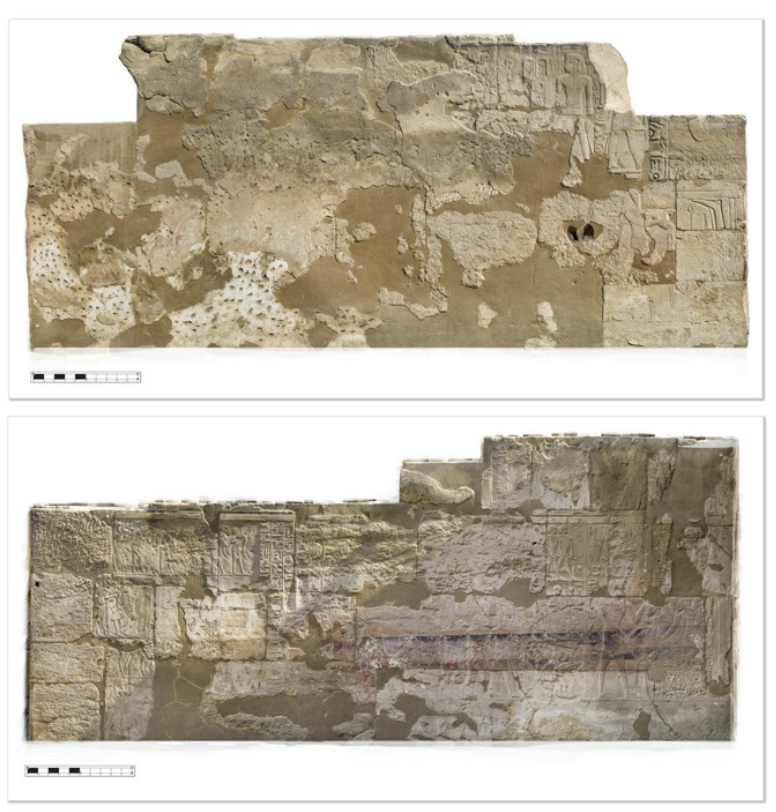

Figure 17: NW \& NW Walls. The north west (top) and north east (bottom) walls of the Imperial Cult Chamber. Murray/The Epigraphic Survey 2017.

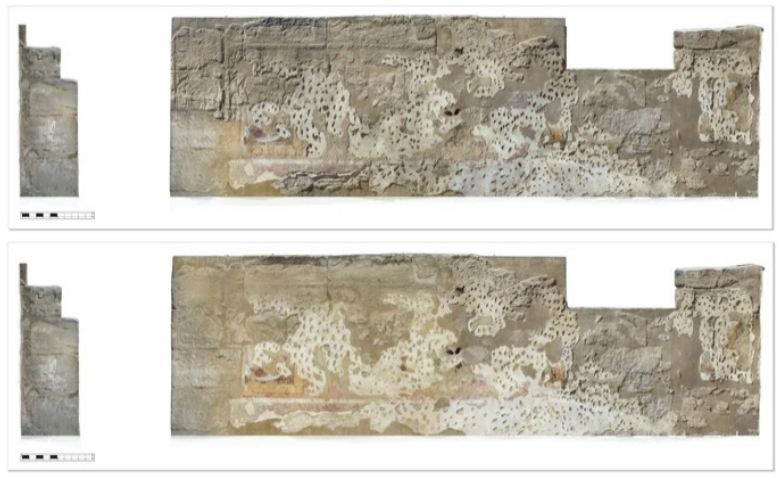

Figure 18: The West Wall. The west wall in direct raking sunlight (top) and diffused indirect ambient sunlight (bottom). Murray/The Epigraphic Survey 2017.

\section{Niche Documentation}

During the winter of 2017-2018, the author worked with Vertes to produce an unravelled, flattened view of the niche apse from which epigraphic documentation in the chamber could be finally completed. This documentation objective was realized in 2019 (Fig. 19).

In order to achieve this result, and with an understanding that photogrammetric documentation efforts would be expanded upon in future seasons throughout the Survey's temple concession, the author implemented a local coordinate survey with the assistance of master stone mason, Frank Helmholz. Though the survey coordinates and origin point were new, the physical baseline points used pre-existing iron survey markers hammered into place by an Egyptian Military engineering team some 30 years previous during an overhaul and reconstruction of the A III Court. It is hoped that the choice of these established permanent markers will allow the more recently implemented local coordinate system to integrate with previous surveys if-and-when these datasets are made available, as well as shift to global coordinates as needed. In consultation with colleagues Yves Egels (ENSG) and Emmanuel Laroze (CNRS-UMR 8167) the best target positions in order to unravel the apse were determined and then measured (Fig. 20). These measurements when integrated with the photogrammetric dataset and overall $0.634 \mathrm{px}$ target accuracy returned averaged error margins of $1.4 \mathrm{~mm}$.

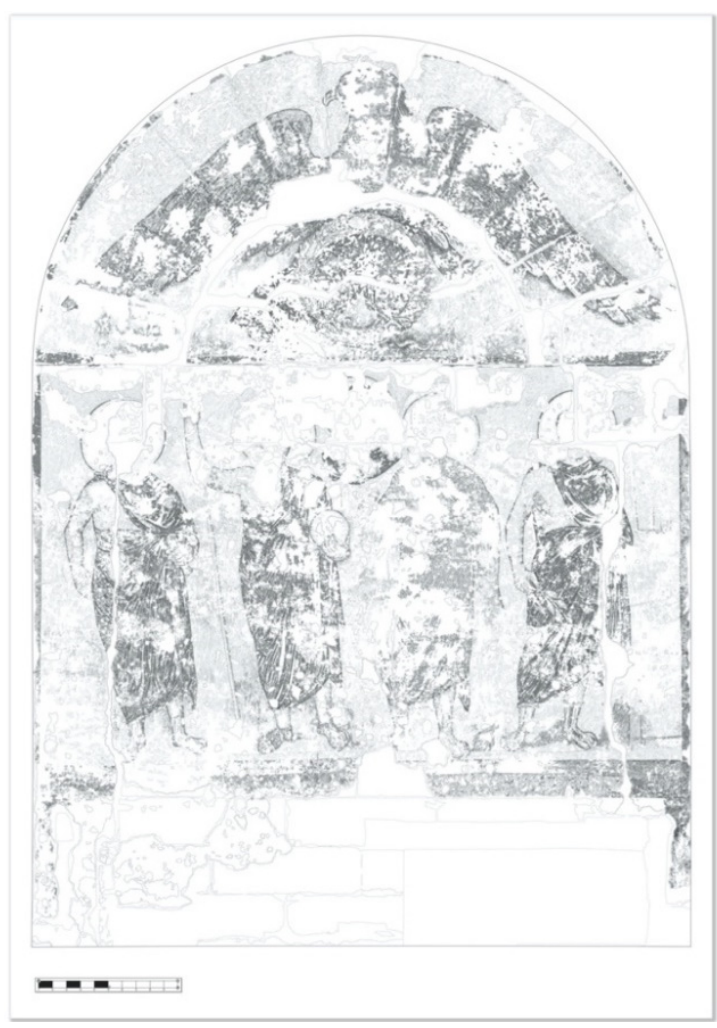

Figure 19: The Niche Apse. Representation of the late Roman frescoes in the niche in the south wall of the Imperial Cult Chamber. Vértes/The Epigraphic Survey 2019.

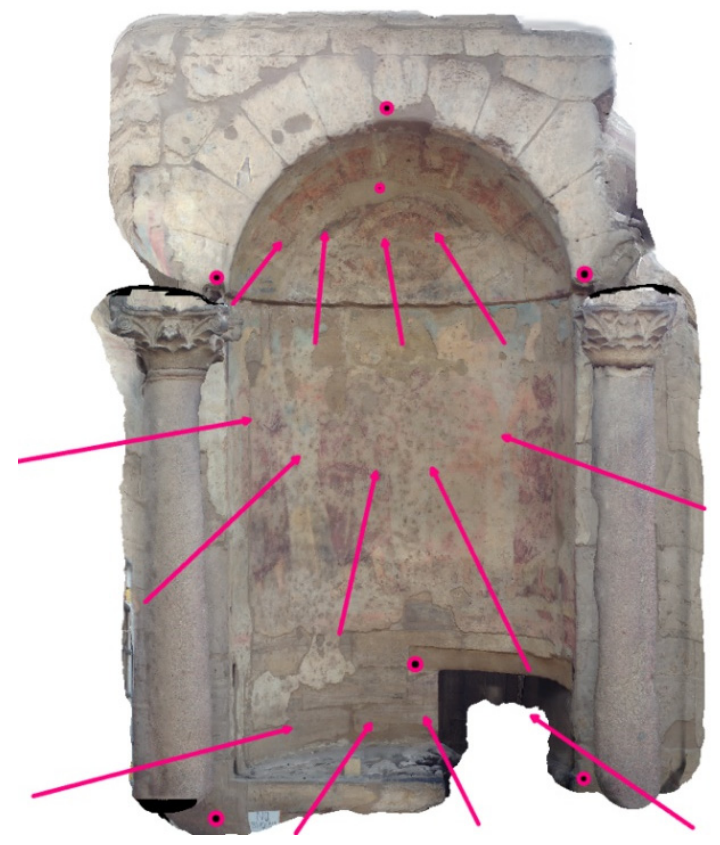

Figure 20: Niche Apse Trial. Mock up model indicating the optimal target positions (pink circles with black dots) for measuring the niche apse; a total of 7 targets. Egels 2017. 
A sturdy yet easily moved set of scaffolding was set up by the Survey's raise (foreman) Bedaowy Abd' Alaa and Ahmed Abdou, and this was used to achieve the right vertical $(Z)$ height within the apse. The scaffolding was set up in three different footprint positions that allowed the author to maintain a $1.5-2 \mathrm{~m}$ distance as perpendicular as possible to the curve of the niche in any given position and at any given height. Photos were shot from bottom to top during lulls in tourist activity, from a series of 14 levels in approximately $1 / 2 \mathrm{~m}$ increments resulting in a 250 -photo dataset (Fig. 21). Nine of these 250 photos were taken as a control set from a distance of $+/-11 \mathrm{~m}$ in order to consolidate and strengthen the sparse cloud tie points.

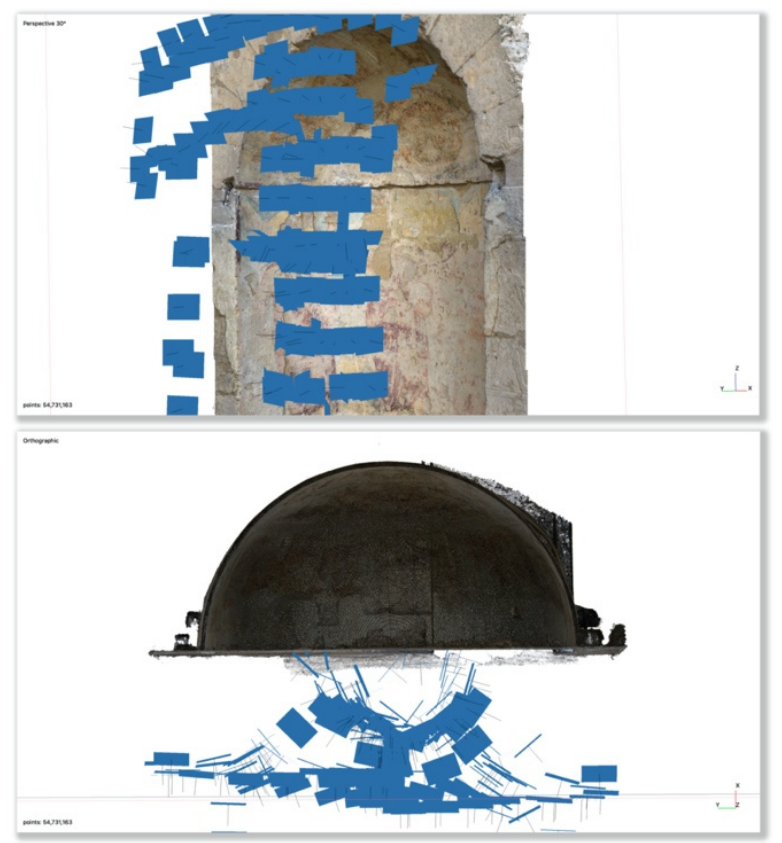

Figure 21: Apse Camera Positions. Two screen shots of the camera positions used for the niche photogrammetry; a dataset of 250 images. Murray/The Epigraphic Survey 2018.

As with the south west wall, the apse was photographed in the early afternoon while in shadow in indirect ambient sunlight, and as with the north, west and south west walls, an X-rite colour checker was photographed and used to maintain correct colour calibration in post process. Hasselblad's proprietary RAW files were imported into Adobe Lightroom, adjusted with a lens profile specifically made for the Mamiya-Sekor Z 50mm f/4.5 then colour corrected and fine-tuned for exposure, shadow and highlights before being exported as high-resolution JPEGS with the least amount of compression. Agisoft PhotoScan/Metacshape was used to build the model at medium resulting in a $54.7 \mathrm{M}$ points, extrapolated to a mesh of $3.6 \mathrm{M}$ triangles, and textured at $36 \mathrm{~K}$.

This PhotoScan model was exported as a .PLY and imported into Yves Egels' Cumulus software (Cumulus, 2014) and the apse was unravelled twice: once using a spherical projection for the semidome portion containing the representation of Jupiter in the form of an eagle, and once using a cylindrical projection for the remaining lower portion containing the four tetrarchs (Fig. 22). Cumulus relies on the GeoTIFF format to accurately unravel texture in conjunction with mesh. These two results were aligned and combined in Adobe Photoshop to produce the final result at the requested scale of 1:4@ 400ppi (Fig. 23).
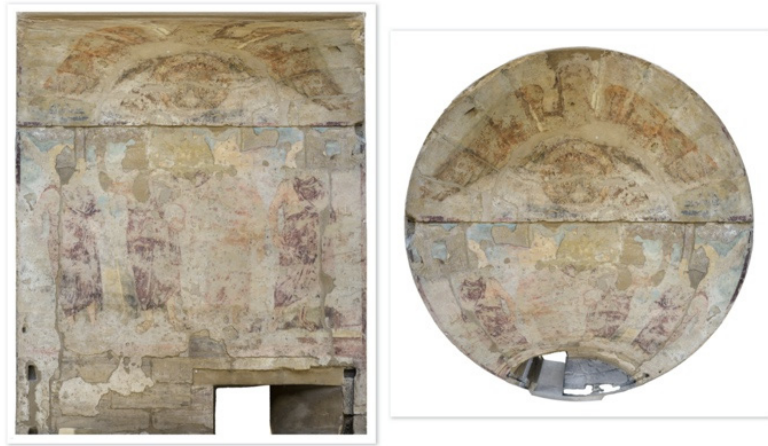

Figure 22: Apse Projections. The cylindrical (left) and spherical (right) projections used to unravel and flatten the apse niche for epigraphic documentation. Murray/The Epigraphic Survey 2018.

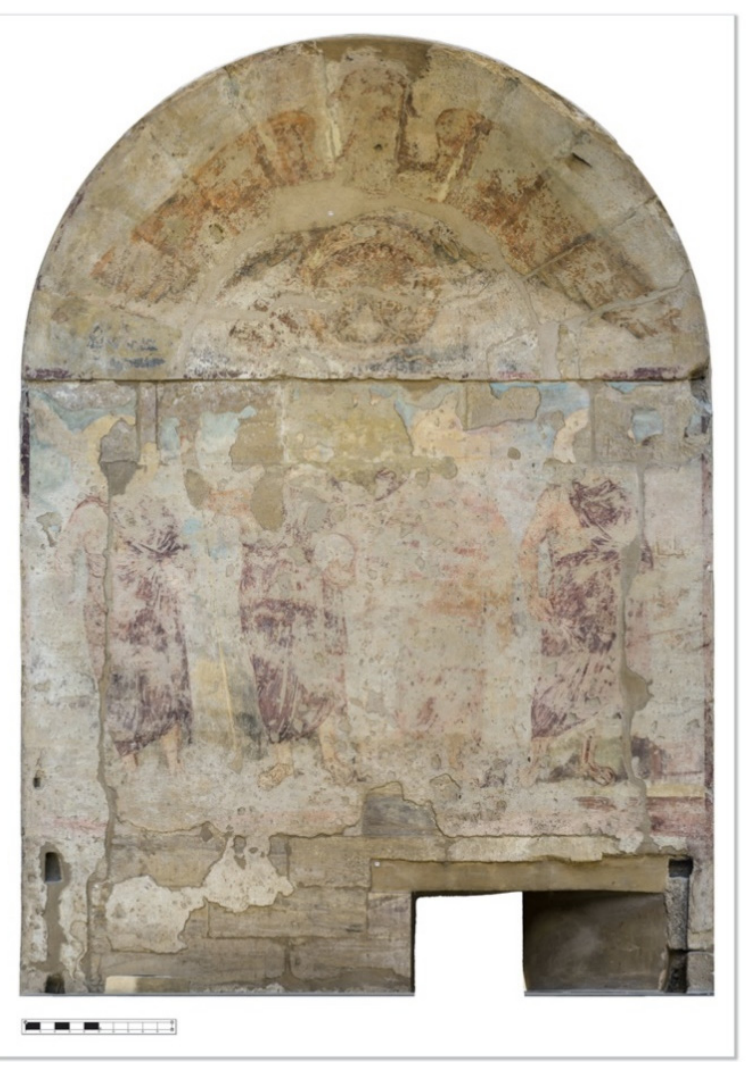

Figure 23: The Unravelled Apse. The overall perspective corrected (flattened) niche in the south wall of the Imperial Cult Chamber. Murray/The Epigraphic Survey 2018.

\section{Conclusions}

The resulting epigraphic fresco documentation stands unparalleled (Fig. 24) and as mentioned by Jones \& McFadden (2015) regarding the 2005-2008 conservation efforts in Art of Empire, becomes yet one more piece in the cultural biography of the Chamber itself, inevitably influencing how future generations will perceive the frescoes, and in so doing, becoming part of the ever evolving physical and intellectual landscape in which they exist. 


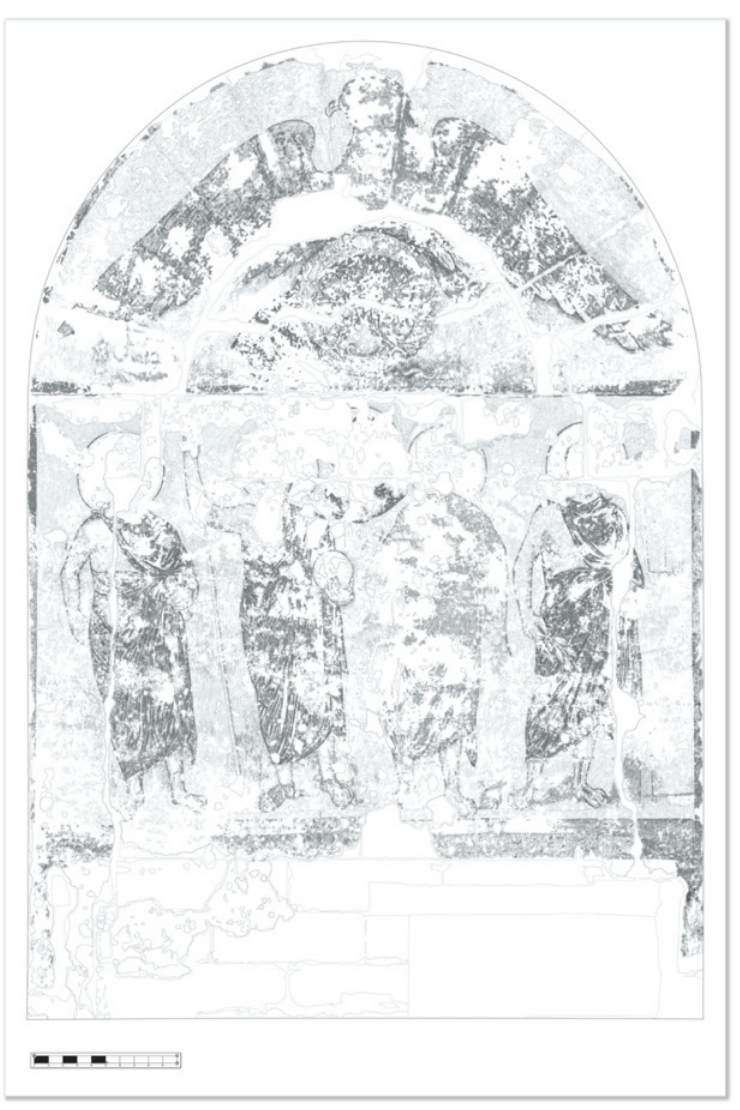

Figure 24: Luxor Temple Roman Wall Paintings.

Representation of the late Roman frescoes in relation to 18th Dynasty reliefs; original at 1:4 @ 400ppi. Vértes/The Epigraphic Survey 2019.

As the objectives for this project were two dimensional in nature and focused predominately on texture, medium settings were used for the modelling, however it should be noted that the aforementioned $0.0845 \mathrm{~mm} / \mathrm{px}$ ratio run on the high setting in Metashape delivers a dense point cloud of $43 \mathrm{M}$ points $\mathrm{per} / \mathrm{m}^{2}$, while on the ultra-high setting, delivers $193 \mathrm{M}$ points per $/ \mathrm{m}^{2}$. Though the high setting falls short, the ultra-high setting delivers well over the 100M points per/m $\mathrm{m}^{2}$ established by Factum Arte (2020) for routing physical facsimile reproductions in the Valley of the Kings (Factum Foundation, 2014), and in terms of the desired capabilities and outputs of a digital twin, is worth noting.
In the 2018-2019 field season the Imperial Cult Chamber was laser scanned from 24 different positions using a Leica BLK 360 by Alexis Pantos with assistance from the author. Along with the photogrammetry described above, the goal is to combine and optimize these datasets for eventual game engine and web browser display. It is hoped that along with 2D printed materials, Vértes' epigraphic fresco documentation will be presented in a georeferenced 3D virtual environment similar to the efforts of the Swedish Pompeii Project (Dell'Unto et al, 2016) (Fig. 25).

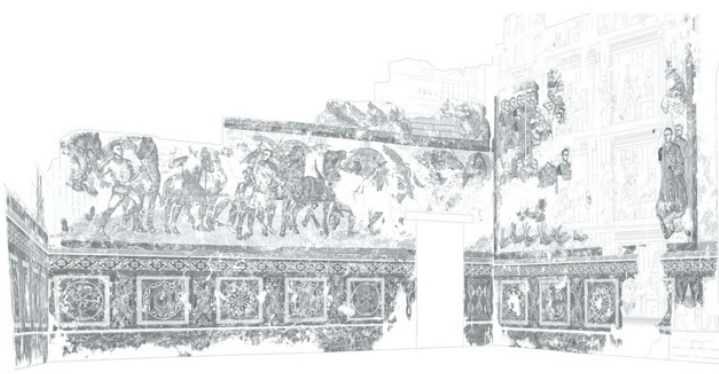

Figure 25: Roman Wall Painting Reconstruction. A reconstruction of the Roman Wall paintings in the Imperial Cult Chamber combining rectified archival material with current epigraphic documentation. View based on Wilkinson's sketchbook. Vértes 2019.

Ultimately, an augmented reality app that allows a user to experience the fresco documentation along with the Epigraphic Survey's past and future documentation efforts, while onsite, would be of great help not only to interested colleagues and researchers, but the visiting public at large.

\section{Acknowledgements}

The illustrations and photographs (orthomosaics) presented in this article acknowledged as 'Surname/The Epigraphic Survey 20XX' are courtesy of the Oriental Institute of the University of Chicago and forthcoming in the Epigraphic Survey's Luxor Temple Series, Volume III.

Many thanks are due to the editors and authors of Art of Empire: Jones, McFadden, Ruffini, Heidel \& Johnson, De Cesaris, Sucato and Ricchi, without whom the introduction and background in this paper would have been neither succinct nor so well informed.

\section{References}

Cumulus. (2014). Yves Egels freeware. Retrieved October 30, 2016, from http://yves.egels.free.fr/Soft/telecharger.html

Chandelier, L., Egels, Y., Héno, R. \& Schelstraete, D. (2013). Prise de Vue Photogrammatrique. Ecole Nationale des Sciences Géographiques, Département Imagerie Aérienne et Spatiale: Photogrammétrie Rapprochée, V.3 (41-48).

De Cesaris, L., Sucato, A., \& Ricchi, E. (2015). Conservation of the Fragments of Roman Wall Paintings in the Imperial Cult Chamber of Luxor Temple. In M. Jones \& S. McFadden (Eds.), Art of Empire: The Roman Frescoes and Imperial Cult Chamber in Luxor Temple. (Chapter 5, pp. 89-103) ISBN 978-0-300-16912-6.

Deckers, J. G. (1979). Die Wandmalerei im Kaiserkultraum von Luxor. Iahrbuch des Kaiserlich Deutschen Archäologischen Instituts, 94, 600-652.

Dell'Unto, N., Landeschi, G., Leander Touati, A.-M., Dellepiane, M., Callieri, M., \& Ferdani, M. (2016). Experiencing Ancient Buildings from a 3D GIS Perspective: a Case Drawn from the Swedish Pompeii Project. Journal of Archaeological Method and Theory, 23, 73-94. https://doi.org/10.1007/s10816-014-9226-7

Huggett, J. (2019). Virtually Real, or Really Virtual: Towards a Heritage Metaverse? Studies in Digital Heritage, 4, 1 (1-15). https://doi.org/10.14434/sdh.v4i1.26218 
Heidel, J. B. \& Johnson, W. R. (2015). The Tetrarchic Architectural Renovation of Luxor Temple: Context, Significance and the Amun Cult. In M. Jones \& S. McFadden (Eds.), Art of Empire: The Roman Frescoes and Imperial Cult Chamber in Luxor Temple. (Chapter 3, pp. 39-59) ISBN 978-0-300-16912-6.

Jones, M. \& McFadden, S. (2015). Introduction. In M. Jones \& S. McFadden (Eds.), Art of Empire: The Roman Frescoes and Imperial Cult Chamber in Luxor Temple. (pp. 1-11) ISBN 978-0-300-16912-6.

Jones, M. (2015). From Ruins in a Landscape to a Monument on Display: A Conservation History of the Imperial Cult Chamber and Its Paintings. In M. Jones \& S. McFadden (Eds.), Art of Empire: The Roman Frescoes and Imperial Cult Chamber in Luxor Temple. (Chapter 4, pp. 61-87) ISBN 978-0-300-16912-6.

Jones, M. (2015). Appendix: John Gardner Wilkinson's Documentation of the Imperial Cult Chamber and Frescoes. In M. Jones \& S. McFadden (Eds.), Art of Empire: The Roman Frescoes and Imperial Cult Chamber in Luxor Temple. (Appendix, pp. 154-168) ISBN 978-0-300-16912-6.

McClain, J. B. (2020). The Chicago House Method. In V. Davies \& D. Laboury (Eds.), The Oxford Handbook of Egyptian Epigraphy And Palaeography. (Chapter III .4, pp. https://doi.org/10.1093/oxfordhb/9780190604653.001.0001

McFadden, S. (2015). The Luxor Temple Paintings in Context: Roman Visual Culture in Late Antiquity. In M. Jones \& S. McFadden (Eds.), Art of Empire: The Roman Frescoes and Imperial Cult Chamber in Luxor Temple. (Chapter 6, pp. 105-133) ISBN 978-0-300-16912-6.

Monneret de Villard, U. (1953). The Temple of the Imperial Cult at Luxor. Archaeologia of Miscellaneous Tracts Relating to Antiquity, c. 1 v.95 (85-105).

Recording with the Lucida 3D Scanner. (2020). Factum Arte. Retrieved October 26, 2020, from http://www.factumarte.com/pag/1552/recording-with-the-lucida-3d-scanner

The Facsimile of Tutankhamun's Tomb: Overview. (2014). Factum Foundation. Retrieved October 26, 2020, from https://www.factumfoundation.org/pag/1548/the-facsimile-of-tutankhamuns-tomb-overview

Vértes, K. (2019). Documenting and Reconstructing the Late Roman Murals in the Roman Vestibule at Luxor Temple. XII ICE Cairo, Forthcoming. Cairo, Egypt.

Vértes, K. (2020). Tradition and Innovation in Digital Epigraphy. In V. Davies \& D. Laboury (Eds.), The Oxford Handbook of Egyptian Epigraphy And Palaeography. (Chapter III .7, pp. 624-650). https://doi.org/10.1093/oxfordhb/9780190604653.001.0001

Wilkinson, J. G. (1852-6). Oxford, Bodleian Libraries, MS. Wilkinson dep. d. 34. Sketchbook, Retrieved November 30 , 2020, from https://archives.bodleian.ox.ac.uk/repositories/2/archival_objects/85379 